\title{
Jung's Synchronistic Interpretation of the Near-Death Experience: An Unnecessary Mystification
}

\author{
L. Stafford Betty, Ph.D. \\ California State University, Bakersfield
}

\begin{abstract}
In his long essay on synchronicity, Carl Jung enlisted the help of a relatively complete but little known near-death experience (NDE) to illustrate his thesis. This NDE was not the famous one he himself had in 1944 , but one related to him by a patient. It contained all four of Bruce Greyson's NDE components, most notably the paranormal. Jung regarded the patient's experience as a good example of synchronicity, by which he meant "the simultaneous occurrence of a certain psychic state with one or more external events." What is remarkable, and problematical, about his view of synchronicity was that it was acausal. I develop and defend an alternative epistemology involving causality: While paranormal knowledge is hard to explain, there is no good reason to remove it from cause-and-effect discourse. I close by speculating why Jung chose to conceive of sychronicity in a manner so mystifying.
\end{abstract}

KEY WORDS: near-death experience; Jung; synchronicity; paranormal; materialism.

Carl Jung died in 1961, a few years before anyone knew that the near-death experience (NDE) was a common enough phenomenon to study in a systematic way. Yet he himself had had an NDE in 1944 (Jung, 1961, pp. 289-93), and he described another that one of his patients had (Jung 1969, pp. 507-09) sometime before 1952. We know, furthermore, that he was familiar with two other NDEs described by George Tyrrell (1947, pp. 197-201). Needless to say, Jung never referred to any of these as a "near-death experience," as that term was

L. Stafford Betty, Ph.D., is Professor of Religious Studies at California State University, Bakersfield. Reprint requests should be addressed to Dr. Betty at the Department of Philosophy and Religious Studies, California State University, Bakersfield, Bakersfield, CA 93311; e-mail: sbetty@csub.edu. 
not coined until 1975 (Moody, 1975), and he was understandably unaware that his own NDE was anything other than "an extremely strange thing" (Jung 1961, p. 289).

It is not on this more famous NDE, which Bruce Greyson (1993) classified as predominantly "transcendental" in content and feeling, that I will focus on here. Rather it is on his patient's. For it is this case, buried deep in a long and difficult essay on quite another topic, that Jung used as an illustration of "synchronicity." I will try to show why, and to what degree, he resorted to an unnecessary mystification to explain elements of the NDE and how we might more intelligibly speak of it now.

\section{The Case}

Jung introduced the case in these words: "I would like to give an example from my own medical experience. A woman patient, whose reliability and truthfulness I have no reason to doubt, told me that her first birth was very difficult" (1969, p. 507). He proceeded to describe a young woman near death due to loss of blood following a forceps delivery. The NDE commenced in a familiar manner:

The next thing she was aware of was that, without feeling her body and its position, she was looking down from a point in the ceiling and could see everything going on in the room below her: she saw herself lying in the bed, deadly pale, with closed eyes. Beside her stood the nurse. (Jung, 1969, pp. 507-508)

She went on to describe a flustered doctor pacing the floor and her mother and her husband looking on with alarm. Simultaneously she was aware of "a glorious, park-like landscape shining in the brightest colours, and in particular an emerald green meadow with short grass, which sloped gently upwards beyond a wrought-iron gate leading into the park" (Jung, 1969, p. 508). She was certain this scene of "indescribable splendour" was the world she would enter at death, but she was also certain that she would not die. She was so certain of her recovery that "she found the agitation of the doctor and the distress of her relatives stupid and out of place" (p. 508). Altogether she was unconscious for about 30 minutes.

On coming to, she "described in full detail what had happened during the coma" and forced the nurse to admit that the doctor had been "hysterical." The patient "had perceived the events exactly as they happened in reality," Jung wrote $(1969$, p. 508). 
Jung was most impressed by the coincidence between what the comatose patient observed and what actually happened in the room. He was certain the woman "was in a coma and ought to have had a complete psychic black-out and been altogether incapable of clear observation and sound judgment" (1969, p. 509), yet she saw everything that happened. Not only that: "she saw the whole situation from above, as though 'her eyes were in the ceiling,' as she put it" (Jung, 1969, p. 509).

This case is so typical that it sounds as if it might have been lifted from Raymond Moody's Life After Life (1975), the book most responsible for introducing the world to the NDE. Yet Jung was writing 20 years before the appearance of Moody's book. That fact by itself makes the case interesting. Also interesting is the relative "completeness" of the case. It has all four of Greyson's (1993) elements: it is cognitive, affective, paranormal, and transcendental. But it is what Jung did with the case, especially its paranormal component, that makes it especially interesting to me. Judging by its placement in the text, the case was a "star witness" for his famous theory of "synchronicity." This case, along with the other paranormal phenomena Jung surveyed, could have been analyzed in a different, less mystifying way.

Before giving a more coherent interpretation of the NDE and other paranormal experiences, we must first see what Jung had to say about this rather slippery term, synchronicity.

\section{Synchronicity}

Jung explored synchronicity most thoroughly in a long paper titled "Synchronicity: An Acausal Connecting Principle" (1969), originally published in 1952 and translated into English in 1955. At the essay's outset he defined synchronicity as "the simultaneous occurrence of a certain psychic state with one or more external events" $(1969$, p. 441), but the psychic state, he explained, "is not causally derivable" (1969, p. 445) from the external events. He mainly had in mind knowledge derived by telepathy, the existence of which he did not question. As he saw it, then, there was a situation in the external world, and there was extrasensory knowledge of the situation. One might suppose that the knowledge was caused by the situation, but Jung denied this:

How could an event remote in space and time produce a corresponding psychic image when the transmission of energy necessary for this is 
not even thinkable? However incomprehensible it may appear, we are finally compelled to assume that there is in the unconscious something like an a priori knowledge or an "immediacy" of events which lacks any causal basis. At any rate our conception of causality is incapable of explaining the facts. (Jung, 1969, p. 447)

It was at this point that the problem seemed on the verge of clarifying itself. In the last sentence Jung seemed to make a distinction between causality understood in the abstract and "our conception of causality." By that last phrase he meant the materialist's conception of causality, the kind of causality that is "bound up with the existence of space and time and physical changes, and consists essentially in the succession of cause and effect" (Jung, 1969, p. 446-447) and depends on a "demonstrable quantity" (p. 446). Was Jung denying only that particular version of causality as it related to extrasensory perception, while allowing some other version of causality at the time ungrasped? Was he implying that our commonsensical (as opposed to a strictly scientific) understanding of causality might apply to extrasensory perception and might undergird what he is calling synchronicity?

Later in the essay he postulated "some other nervous substrate in us, apart from the cerebrum, that can think and perceive ... events which have no causal connection with organic processes" (Jung, 1969, p. 509). This substrate "is absolutely different from the cerebrospinal system in point of origin and function" and "can evidently produce thoughts and perceptions just as easily as the latter" (pp. 510-511). It might seem, therefore, that Jung was denying only a particular kind of causality: that which is based on organic processes. And synchronicity would be the term for a different kind of causal relationship, one that was not based on organic processes, "one that has nothing to do with materialism" (p. 512).

For whatever reason Jung did not develop this line of thought. Instead he wrote that the equivalence between the external situation and the extrasensory perception of the situation was acausal in a more radical sense. It was not the case merely that the cause of the perception was unknown; rather "a cause is not even thinkable in intellectual terms; ... for a causality which presupposes space and time for its continuance can no longer be said to exist and becomes altogether unthinkable" (Jung, 1969, p. 519). So unthinkable was the relation between external situation and extrasensory knowledge of it that a new word had to be introduced to suggest it; and that word, synchronicity, "produces a picture of the world so irrepresentable as to be completely baffling" (p. 513). Doing his best to reduce the mystery, 
Jung supplied for the reader a synonym of dubious helpfulness: "acausal orderedness" (p. 516).

\section{An Alternative to Synchronicity}

I think that Jung exaggerated the "unthinkability" of paranormal knowledge, and therefore of the paranormal NDE like the one he described. I think that most of us, regardless of our education, know in a general way what causality is: the quality that something has when it brings about or in some way triggers a change in something else. I do not know why we should feel compelled to grasp exactly how the change occurs before we use the language of causality. Doctors tell us that migraine headaches are "caused by" the release of serotonin into the bloodstream from its storage sites in the body. But have they really told us what causes the pain? No, they have told us only what creates the condition resulting in the pain. How brain states generate conscious experience is completely unknown. Yet we do not hesitate to speak of the brain as the cause of experience. Why, then, should we hold ourselves to a higher standard when trying to account for paranormal knowledge?

I therefore think Jung went too far when he wrote that a cause for paranormal knowledge or extrasensory perception was "not even thinkable in intellectual terms" (p. 519). I think he should have said that the mechanics of the cause were unthinkable. If he had applied the word synchronicity to a mysterious kind of causation whose mechanics were presently unknown, I would have no quarrel with him.

\section{How the Alternative Applies to the Paranormal NDE}

Jung's patient's NDE would be considered "paranormal" in Greyson's classification because its most interesting feature is the woman's ability to describe in detail and with accuracy what was happening in her hospital room when she was in a coma. We have seen how she looked down from a point near the ceiling and "saw" her own body, the nurse, the desperate doctor, and her relatives interacting. Her case is typical of paranormal NDEs. More interesting cases involve patients who not only leave their body but the room, the hospital, and sometimes even the country, but who also "see" people or things or events in these distant places that are later verified by witnesses who were there. The most remarkable paranormal cases involve blind 
people who accurately see real situations for the first time in their lives during their NDE (Ring and Cooper, 1999).

In addition there are cases of comatose NDErs who report seeing the spirits of deceased relatives and friends. The same are reported by dying but still conscious (not comatose) people (Barrett, 1926; Callanan and Kelley, 1992). While it is tempting to dismiss these apparitions as hallucinations, there are good reasons for not doing so, though they are outside the scope of this paper.

So what causes all this mysterious seeing that NDErs report? Or does it make more sense to deny causality to them? I do not hesitate to ascribe causality to them, and in the following straightforward manner. Jung's patient really did see what was happening in her hospital room - on this point Jung and I are in agreement - and there were identifiable causes of her experience. These causes were the actual presence of bodies - her own, the nurse's, the doctor's, and her relatives' - in the room. If they had not been there, she would not have seen them. They were causes in the same sense that the people and pets we see in our homes are causes of our experience of them. It is true that we know more about the physiological mechanics of seeing our family members than we know about NDErs who see real things while out of their body, but the difference is not all that great since in the last analysis all conscious experience, whether in the body or out of it, is utterly unexplainable.

Someday we may be able to give an account of how people see during an out-of-body experience. Perhaps the explanation will resemble that of the ancient Hindus who described layers of subtler bodies just under our skin with subtler senses intact. Many NDErs tell us they have a definite sense of being embodied while out of their physical bodies. If they are embodied, then they may be thinking with subtle brains and seeing with subtle senses. If that is so, we are closer to solving the mystery that Jung found so baffling. Rather than saying there is no causality for the NDEr's paranormal knowledge, we could say that there are two aspects to the cause: the actual presence of what is seen, and a subtle sensory apparatus belonging to a subtle body that does the seeing. Beyond that we could not say, but saying that much is helpful, helpful in the sense that it helps us grasp why NDErs accurately report what they have no business seeing according to conventional, materialistic science. In normal situations we use the language of causality to account for the things that we see. There is no compelling reason to drop the habit when NDErs describe with accuracy the things that they see. 


\section{Postscript: Why Jung Packaged Synchronicity the Way He Did}

Why did Jung resist this accommodation to common sense so tenaciously? The key lies in his rejection by his colleagues, especially Sigmund Freud, who had been a father figure to him. The rejection came in 1912 with the publication of Jung's Symbols of Transformation. Jung wrote many years later: "After the break with Freud, all my friends and acquaintances dropped away. My book was declared to be rubbish; I was a mystic, and that settled the matter" (1961, p. 167). In his book C. G. Jung: Lord of the Underworld (1984), Colin Wilson presented compelling evidence that Jung fretted about his professional isolation for the rest of his life. About Jung's essay on synchronicity specifically, Wilson wrote: "all this is dressed up in talk about causality and non-causality ... to give it the appearance of a scientific hypothesis" (1984, p. 116). He added that Jung was "obviously worried about his scientific image" (p. 122).

Jung never got over the need to court his materialist colleagues even as he scorned them. He might have been a mystic, he might have believed in the soul, even an afterlife, but at least he thoroughly understood what they believed in. They believed in cause and effect; they believed that the mind was at best an epiphenomenon of chemical events in the material brain; they believed in matter and rejected spirit; and they believed that so-called paranormal events were figments of the imagination and needed no theory to explain them because they did not exist. He understood their biases and he could speak their language, even accommodate his theories to that language, and thereby show the world that he was as legitimate a scientist as they.

James Forsyth shared this conviction about Jung and wished, as I do, that Jung had gone in a different direction: "Instead of insisting on the scientific nature of his work, perhaps Jung would have better served his cause by insisting on the validity of this experiential type of knowledge as complement to scientific knowledge as that term is generally understood" (Forsyth, 2003, p. 58). If he had, he might not have felt the need to "clip out" paranormal knowledge from more conventional knowledge and dress it up so mystifyingly. Perhaps he would have resisted the temptation to surrender cause-and-effect thinking to his materialist colleagues, as if they alone would know what to do with it. Instead of courting their good opinion of him, he might have staked out a different kind of territory where causes and their effects were more shadowy and mysterious and harder to pin 
down, but not any the less real for being so. If that had happened, I doubt that he would have invented the word synchronicity to explain the paranormal aspects of his patient's NDE when already existing terms like out-of-body experience, extrasensory perception, and telepathy served perfectly well (Wilson, 1984).

\section{References}

Barrett, W. (1926). Death-bed visions. London, England: Methuen.

Callanan, M., and Kelley, P. (1997). Final gifts: Understanding the special awareness, needs, and communications of the dying. New York, NY: Poseidon Press.

Forsyth, J. (2003). Psychological theories of religion. Upper Saddle River, NJ: Prentice Hall.

Greyson, B. (1993). Varieties of near-death experience. Psychiatry, 56, 390-399.

Jung, C. G. (1969). Synchronicity: An acausal connecting principle. In The collected works of C. G. Jung, Vol. 8, $2^{\text {nd }}$ ed. (Pp. 417-531). Princeton, NJ: Princeton University Press. (Original work published in 1952)

Jung, C. G. (1961). Memories, dreams, reflections. (A. Jaffe, ed.). New York, NY: Pantheon.

Moody, R. (1975). Life after life. Covington, GA: Mockingbird Books.

Ring, K., and Cooper, S. (1999). Mindsight: Near-death and out-of-body experiences in the blind. Palo Alto, CA: William James Center for Consciousness Studies/Institute of Transpersonal Psychology.

Tyrrell, G. N. M. (1947). The personality of man. Baltimore, MD: Penguin.

Wilson, C. (1984). C. G. Jung: Lord of the underworld. Wellingborough, England: Aquarian Press. 